\title{
A Technology Assessment Tool for Evaluation of VOC Abatement Technologies from Solvent Based Industrial Coating Operations
}

\author{
Dhananjai S. Borwankar, William A. Anderson and Michael Fowler \\ Additional information is available at the end of the chapter
}

http://dx.doi.org/10.5772/45745

\section{Introduction}

Ground level ozone detrimentally effects local air quality. In mammals, ground level ozone causes damage to the upper respiratory tract (Farley, 1992), while in plants, it can inhibit photosynthetic activity through complex interactions effecting plant structure (Cape, 2008). Ground level ozone is primarily formed through the photochemical reaction of volatile organic compounds (VOCs) and nitrogen oxides (NOx) (Farley, 1992). Therefore, in an effort to improve local air quality, countries and various regions around the world have begun implementing regulations and guidance documents to curb VOC emission rates.

Canada, the United States, the European Union, and the United Kingdom are among those countries or regions which have implemented guidance documents, mandatory emission limits, or mandatory emission reporting. These tools allow governments to increase the business risk associated with releasing VOC emissions. The premise is that by increasing the business risk associated with emitting these compounds will compel industries to handle their emissions with greater responsibility. VOCs are typically emitted from industrial operations that utilize products such as solvents, thinners, degreasers, cleaners, lubricants, coatings and liquid fuels (Doble \& Kumar, 2005). Therefore industries targeted by these types of regulatory measures include industrial printing, coating and painting operations, metal finishing facilities, and petrochemical operations.

The ideal (and most effective) pollution treatment solutions normally involve removing the pollution source from the process. This would involve substitution of current VOC based coatings with low or no VOC based coatings. Secondary pollution abatement strategies involve alteration of the process itself to reduce the overall contaminant processed and released. An example of this would involve altering (updating) of spray equipment to 
increase the transfer efficiency of the coating being applied onto the part. Unfortunately, due to very long and costly approval procedures for new processes and materials, these types of solutions tend to be prohibitive to implement, and therefore industries tend to use the remaining category of pollution treatment solutions, "end of pipe" or "add on" solutions.

There are many "end of pipe" technologies currently available that can effectively reduce VOC emissions, however, in many cases implementation of these technologies will substantially increase facility costs, downtime, and/or maintenance. Subsequent to implementation, facility managers are found having to invest significant time and resources to handle and operate a system that by itself is not "a value added" process, and hence does not assist the overall productivity of the facility. The result is the implementation of a technology that functions as designed, but does not function in an optimal way with respect to efficiency or productivity.

It is imperative that facility managers are provided with appropriate tools to determine the overall effect implementation of VOC abatement strategies will have on facility performance and their resources prior to implementation. The primary purpose of this work is to outline a methodology (Technology Assessment Tool) to rate various VOC abatement technologies according to the constraint of meeting current and foreseeable future legislative requirements; and the criteria of lifecycle costs and operational flexibility.

In this chapter, a brief review of current mainstream VOC abatement technologies is presented first, with emphasis upon design considerations, operational patterns and criteria, and economics. The discussion then outlines the Technology Assessment Tool methodology that is proposed for the purposes of rating current VOC abatement systems. Finally, a case study using the Technology Assessment Tool methodology will be presented to outline its use in a typical application.

\section{Background}

\subsection{Summary of technologies}

VOC abatement systems are divided into two main categories; destruction, and recovery (Doble \& Kumar, 2005). Destruction technologies involve oxidation of the VOC substances to their most oxidized form; namely, carbon dioxide, and water (for hydrocarbons containing chlorine or sulphur, the exhaust will also include $\mathrm{HCl}$ and $\mathrm{SO}_{2}$ ) (Baukal, 2004). Recovery technologies simply remove the contaminant from the exhaust stream for recovery or further treatment. Figure 1 outlines this division, and includes subcategories for each type of system.

\subsubsection{Destructive technologies}

Destructive technologies use oxidative processes to break down complex VOC compounds. These technologies can be further sub-divided into thermal oxidation and biological oxidation. 


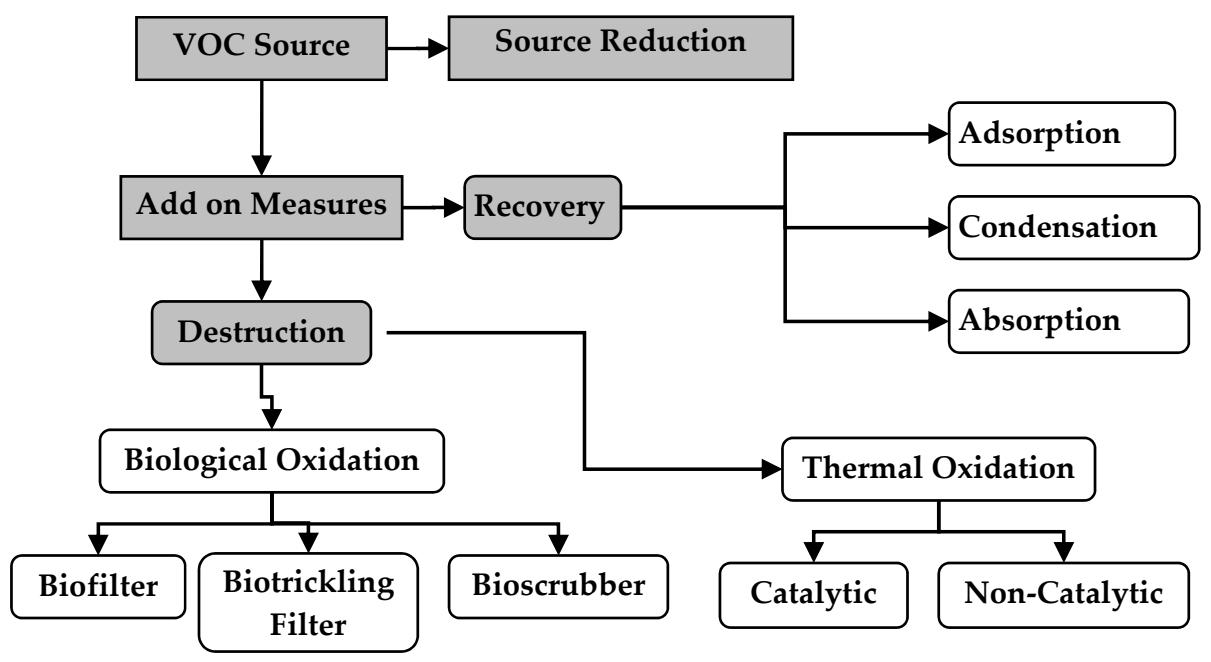

Figure 1. Categorization of VOC abatement technology systems.

Thermal Oxidation. Thermal oxidation (incineration) is the process of raising and maintaining the temperature of a combustible substance above its auto-ignition temperature in the presence of oxygen to complete its conversion to carbon dioxide and water (Baukal, 2004; Moretti, 2002). This process is quite effective, and virtually any gaseous organic stream may be safely incinerated given the proper design, engineering, and maintenance conditions (EPA, 2002).

Design parameters are a function of the feed stream composition, and consist of residence time, combustion chamber temperature, and turbulence (Moretti, 2002; Lewandowski, 2000). Knowledge of these parameters will provide enough information to develop a system lifecycle cost. To minimize capital and operational costs, it is always recommended that the designer attempt to lower the total volume of air that is being sent to the thermal oxidizer. This could mean either concentrating the emission before it enters the thermal oxidizer, or incorporating some sort of air re-circulation system in the process to minimize clean air sent to the system (Shelley et al., 1999). There are practical upper limits to the level of concentration that can be achieved, as most municipal/regional fire prevention bodies and insurance companies limit the concentration of emission going through thermal oxidizers to below 25\% of the lower explosive limit (LEL) (Moretti, 2002; Lewandowski, 2000; Gibson, 1999). This is a preventative measure used to minimize the risk of fires or explosions within the system, and can be considered part of the design constraint.

Another aspect of the design is the recovery of heat. Since these systems are operating between temperatures of $650^{\circ} \mathrm{C}$ to $1,100^{\circ} \mathrm{C}$ it is standard practice to design the system to retain as much heat as possible (Moretti, 2002). One method involves using heat exchangers to transfer heat from the exhaust side of the oxidizer to the feed stream. When this type of heat recovery is used the thermal oxidizer is called a Recuperative Thermal 
Oxidizer (Lewandowski, 2000). The second method of recovering heat involves the use of multiple beds packed with a ceramic type insulating material. Prior to entering the combustion chamber the feed stream is preheated as it is sent through one or more of these heated ceramic beds (Lewandowski, 2000). When the reaction is complete, the hot exhaust stream coming from the combustion chamber is sent through one of the cold ceramic beds exchanging heat with this bed to prepare it for the next volume of feed (Moretti, 2002). The bed packing normally has a very high rate of heat recovery, and can last between 5 to 10 years (Baukal, 2004). These systems are called Regenerative Thermal Oxidizers (RTOs). Both the recuperative and regenerative thermal oxidizers can be referred to as RTOs. Figures 2 and 3 illustrate both styles of RTO. For a typical hydrocarbon emission stream, a characteristic residence time would range between $0.5 \mathrm{sec}$ to $2 \mathrm{sec}$, with temperatures between 650 to $1,100^{\circ} \mathrm{C}\left(1,200-2,000^{\circ} \mathrm{F}\right)$ (Baukal, 2004; Lewandowski, 2000).

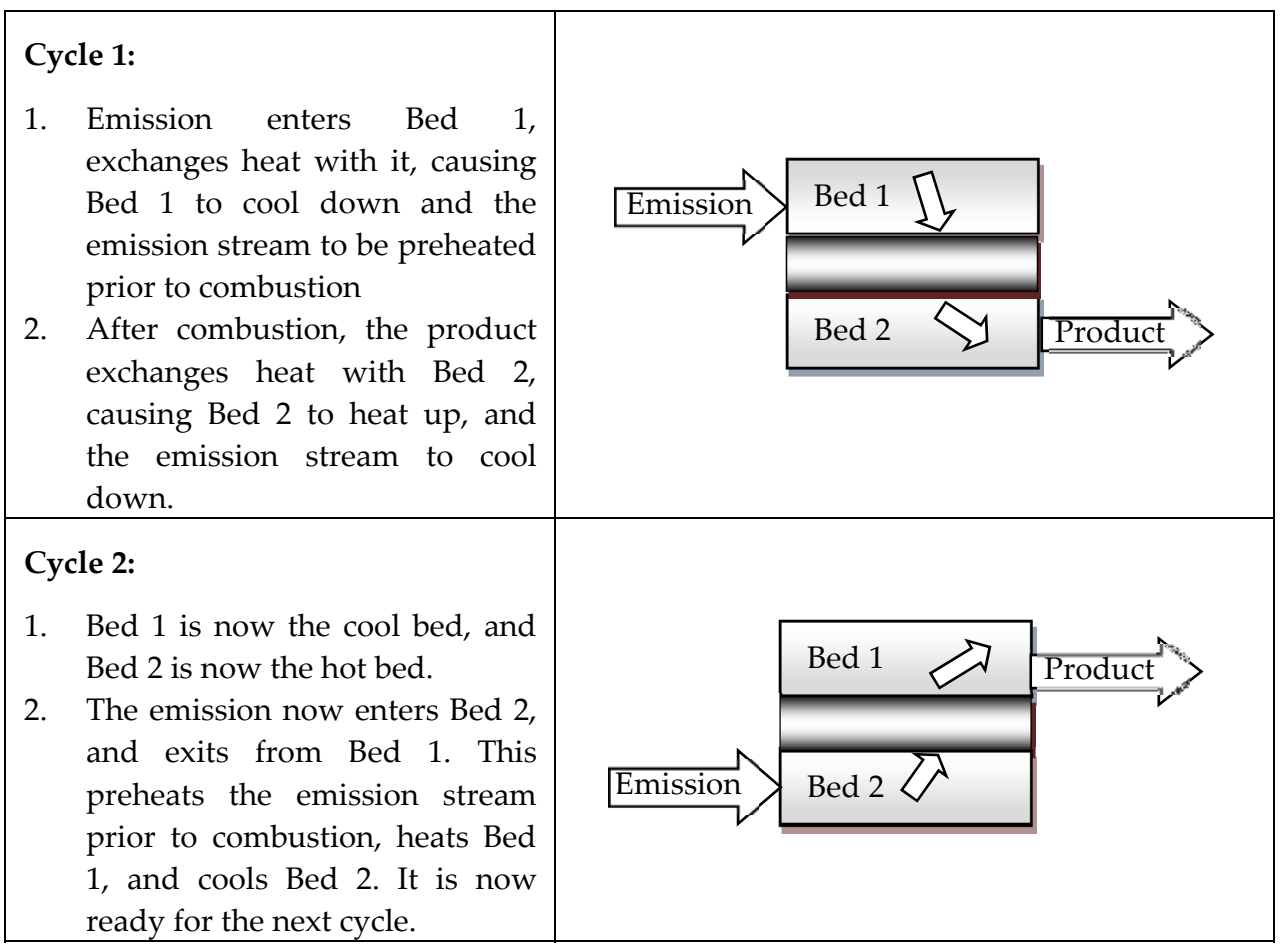

Figure 2. Illustration of the Regenerative type thermal oxidizer operating/heat exchange cycle

Catalytic thermal oxidation operates on the same principle as thermal oxidation, except catalysts are used to increase the reaction kinetics such that combustion can occur at a lower temperature and shorter residence time. Limitations exist on which types of exhaust streams this process can be used, as certain combustion by-products from contaminants may poison the catalyst (for example, corrosive by-products such as $\mathrm{HCl}$ ) (Lewandowski, 2000). 


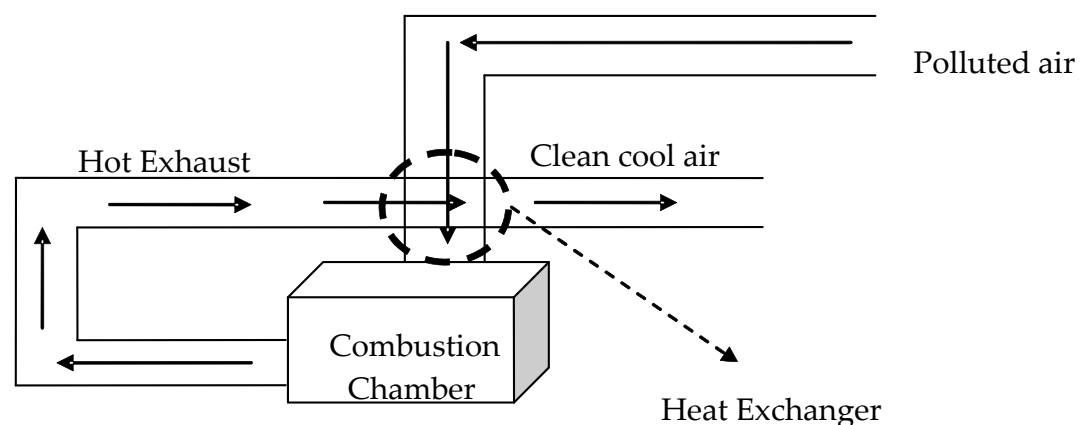

Figure 3. Recuperative type thermal oxidizer heat exchange cycle.

Overall, thermal oxidation is an attractive VOC abatement option because it can be used for complex mixtures of compounds, and it can provide very high levels of control. On the downside, once these systems are designed, they are set for a specific residence time, flow rate range and contaminant type, all of which result in a somewhat inflexible technology (Baukal, 2004; Moretti, 2002). Despite having efficient heat recovery systems, auxiliary fuel costs and electrical consumption arising from air circulation add significantly to the operational costs.

Biological Oxidation. Biological oxidation processes use microbial populations that are able to utilize volatile organic compounds as the primary source for both their catabolic (respiration) and anabolic (growth) requirements (Delhomémine \& Heitz, 2005). The basic concept is to immobilize microorganisms (bacteria and fungi) in a packed porous bed or media through which nutrients and pollutants may flow (Doble \& Kumar, 2005; Devinny et al., 1999). Nutrients, primarily nitrogen and phosphorus, are supplied to the culture through a mixed solution, while the pollutants are allowed to flow through the media. The immobilized microbial population will utilize the pollutants as their primary carbon source for growth and metabolism, oxidizing the VOC components to form carbon dioxide, water, salts and biomass (Devinny et al., 1999). The outcome is a relatively safe process that results in degradation of VOC compounds to carbon dioxide, water, nitrogen oxides, and salts. The main criteria to ensure successful operation lies in controlling the microbial population health and growth rates. This can be done by ensuring the following are met:

1. Carbon, oxygen, water, and nutrient sources are provided to cells to meet their catabolic and anabolic requirements,

2. Carbon, oxygen and nutrient sources provided to the cells are able to reach the cells; and,

3. Biomass and wastes produced as a result of oxidation; do not accumulate in or around the microbial population (Delhoménie \& Heitz, 2005).

Figure 4 provides an illustrative example of a typical biofilter operation. 


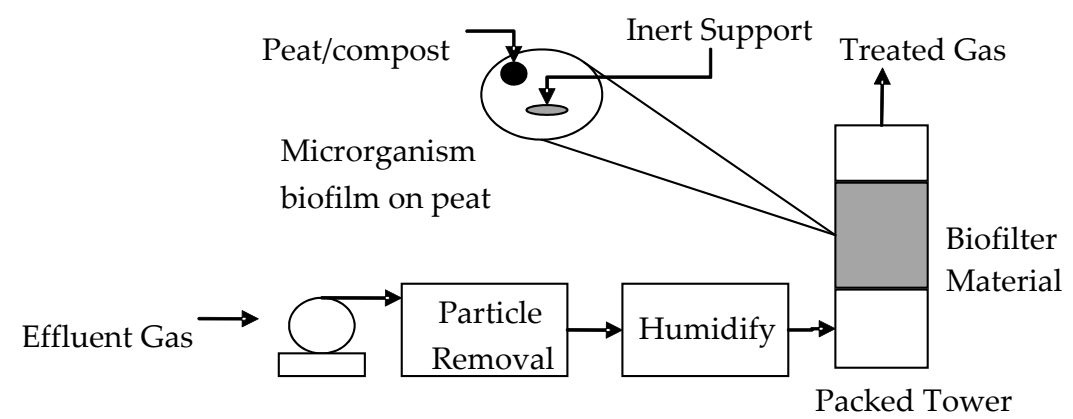

Figure 4. Illustrative depiction of a typical biofilter operation.

These three requirements can be met by understanding the contaminant type (and concentration), the substrate used to support cell growth, the physiochemical parameters of the system, and nutrient and moisture requirements of the bed (Delhoménie \& Heitz, 2005).

The biodegradability of a pollutant type is dependent on the VOC transfer rate to the biofilm, and the VOC biodegradation rate of the microbial population (Delhoménie \& Heitz, 2005). The VOC transfer rate depends upon three basic processes: transport of the VOC and oxygen from the gas phase to the liquid phase, transport of the VOC, oxygen and nutrients from the liquid phase to the surface of the biofilm, and simultaneous diffusion and biotransformation of VOC, oxygen and nutrients within the biofilm (Malhautier et al., 2005). In comparison to the reaction within the cell, diffusion and convection can be on the order of 1000 times slower then the cellular reaction rate (Delhoménie \& Heitz, 2005). This indicates that mass transport (diffusion \& convection) activities in and around the microbial population could be the limiting factor for the overall biodegradation. For VOCs in particular, this occurs because industrial paint exhausts are composed of solvents with poor water solubility. This solubility relates to poor liquid-gas phase interactions, leading to poor pollutant-biofilm absorption rates, thereby potentially limiting overall degradation rates (Delhoménie \& Heitz, 2005).

The support medium is one of the most integral parts of these systems because it provides a safe and habitable environment for microbial populations to grow. The ideal media would have the following characteristics:

1. Resistance to compaction (high tensile strength),

2. Good moisture and nutrient holding capacity,

3. High surface area for bacterial attachment and improved VOC mass transfer,

4. Suitable surface for bacterial attachment (rough, porous, large surface area and hydrophilic); and,

5. $\mathrm{pH}$ buffering capacity (Devinny et al., 1999).

Media such as compost, peat, and soil have excellent water retention capacities, but may be prone to compaction events (Delhoménie \& Heitz, 2005). Compaction has a tendency to 
create fixed pathways throughout the media, limiting gas and nutrient distribution resulting in inefficient conversions, or worse, cell death. Inorganic medias have high tensile strengths which can help minimize compaction, however, microbial populations have trouble adhering to these surfaces (particularly metals and glasses), and can sometimes fall and block gas diffusion pathways (Doble \& Kumar, 2005; Malhautier et al., 2005). Furthermore, inorganic media do not store/hold moisture near as well as organic media do, and therefore will require microbial inoculation and robust systems in place to ensure moisture and nutrient contents in the media remain suitable for the microbial population. Table 1 summarizes the most important properties for various biofilter media (Devinny et al., 1999).

Biological oxidation can be very cost effective provided the system has been designed properly. The main consideration for these systems is in understanding the properties of the emission stream and matching a biological system that can handle the requirements. Unfortunately, because of the complex processes that occur within the biofilter, the design process for these systems can be much more tedious then for other systems (Devinny et al., 1999). High residence times correlate to large bed sizes, or in economic terms, large facility space requirements. Lastly, because of the nature of these systems, increased operator training and effort is required to ensure smooth operation.

\begin{tabular}{|c|c|c|c|c|c|}
\hline Characteristic & Compost & Peat & Soil & $\begin{array}{l}\text { Inert Materials } \\
\text { (e.g. perlite) }\end{array}$ & $\begin{array}{l}\text { Synthetic } \\
\text { Material }\end{array}$ \\
\hline $\begin{array}{l}\text { Indigenous } \\
\text { microbial } \\
\text { population }\end{array}$ & High & Medium-low & High & None & None \\
\hline Surface Area & Medium & High & Low-medium & High & High \\
\hline Air permeability & Medium & High & Low & Medium-High & Very High \\
\hline $\begin{array}{c}\text { Assimilable } \\
\text { nutrient content }\end{array}$ & High & Medium-High & High & None & None \\
\hline Sorption Capacity & Medium & Medium & Medium & Low-High & None-High \\
\hline Lifetime & $2-4$ years & $2-4$ years & $>30$ years & $>5$ years & $>15$ years \\
\hline Cost & Low & Low & Very Low & Medium-High & Very High \\
\hline $\begin{array}{c}\text { General } \\
\text { Applicability }\end{array}$ & $\begin{array}{l}\text { Easy, Cost } \\
\text { effective }\end{array}$ & $\begin{array}{c}\text { Medium, } \\
\text { water control } \\
\text { problems }\end{array}$ & $\begin{array}{l}\text { Easy, low- } \\
\text { activity } \\
\text { biofilters }\end{array}$ & $\begin{array}{c}\text { Needs } \\
\text { nutrients, may } \\
\text { be expensive }\end{array}$ & Prototype \\
\hline
\end{tabular}

Table 1. Summary of Important Properties of Common Biofilter Materials.

\subsubsection{Recovery technologies}

Adsorption, absorption, and condensation are among the leading recovery technologies used to separate VOC emissions from process exhaust streams. An added consideration for these technologies is what to do with the captured contaminant once the process has been completed. In some cases, it is feasible to recover the pollutant with sufficient purity as a 
commodity for resale. In other cases, a final disposal step is required to complete the abatement process.

Adsorption. Adsorption of VOCs involves passing the contaminant-air (adsorbate) mixture through a solid porous bed (adsorbent) to be selectively held by physical attractive forces (EPA, 2002). When the bed becomes saturated, the contaminant-air stream is switched to another bed for adsorption, while the saturated bed is desorbed (regenerated) by passing hot inert gas or steam through the bed, or by reducing the pressure sufficiently to create a vacuum (U.S. Army Corps of Engineers [USACE], 2005; Knaebel, 2007). The removed mixture of inert gas and contaminant, or steam and contaminant is then sent to another process (RTO, decanter, or distillation column) for final disposal or recovery. The design of these systems depends on the chemical characteristics of the VOC (e.g., polarity, molecular weight, size, and other chemical reactivity characteristics), the physical properties of the inlet stream (temperature, pressure, and volumetric flow rate), and the physical properties of the adsorbent (Moretti, 2002; USACE, 2005; Knaebel, 2007).

Together these factors outline how well a particular adsorbate may adsorb onto an adsorbent. In practice there have been many isotherm models postulated that can accurately describe the adsorption-desorption process within specific ranges of temperatures and pressures. Therefore, as long as the pressure and concentrations of contaminants are within the appropriate levels, efficient systems may be designed.

Absorption. Absorption involves the selective transfer of a gas to a specific solvent depending on the solubility of the gas in the liquid, and the mass transfer of the gas to the gas-liquid interface (Cooper \& Alley, 2002). The diffusional component is made up of both molecular and turbulent diffusion, for which turbulent diffusion is orders of magnitude higher. For this reason, absorption systems are designed to maximize turbulence during absorption by flowing both the liquid solvent and gas contaminant through a randomly packed solid column (Cooper \& Alley, 2002). The basic structure of the column and packing material is designed to increase the contact surface area increasing the overall mass transfer of the absorbate to the solvent. A typical system operation would be to percolate the absorbent liquid through the top of the column down, and allow the contaminant gas to pass from the bottom of the column upwards.

Condensation. Separating VOCs by condensation can be accomplished by one of two processes: holding the temperature constant and increasing the pressure (compression condensation), or holding the pressure constant and lowering the temperature (refrigeration condensation), but most condensation systems are of the refrigeration type (Moretti, 2002). For efficient operation these systems are limited to VOCs with boiling points above $38^{\circ} \mathrm{C}$ and relatively high concentrations above 5,000 ppm (Khan \& Ghoshal, 2000; Kohl \& Nielsen, 1997).

\section{Technology assessment: Methodology}

The primary purpose of the assessment is to provide facility managers guidance in choosing the best available abatement technology while also outlining the effect the 
chosen system will have on their facility. In order to accomplish this, each technology must be assessed against key operational parameters that will gauge overall technology effectiveness. These operational parameters will be a function of the design criteria and constraints, which in turn will rely heavily on process characteristics and the emission composition and type. The overall comparison will be made by rating different abatement technologies against criteria including: meeting current and foreseeable future legislative requirements, lifecycle costs and operational flexibility. The basic assessment flow is seen in Figure 5.

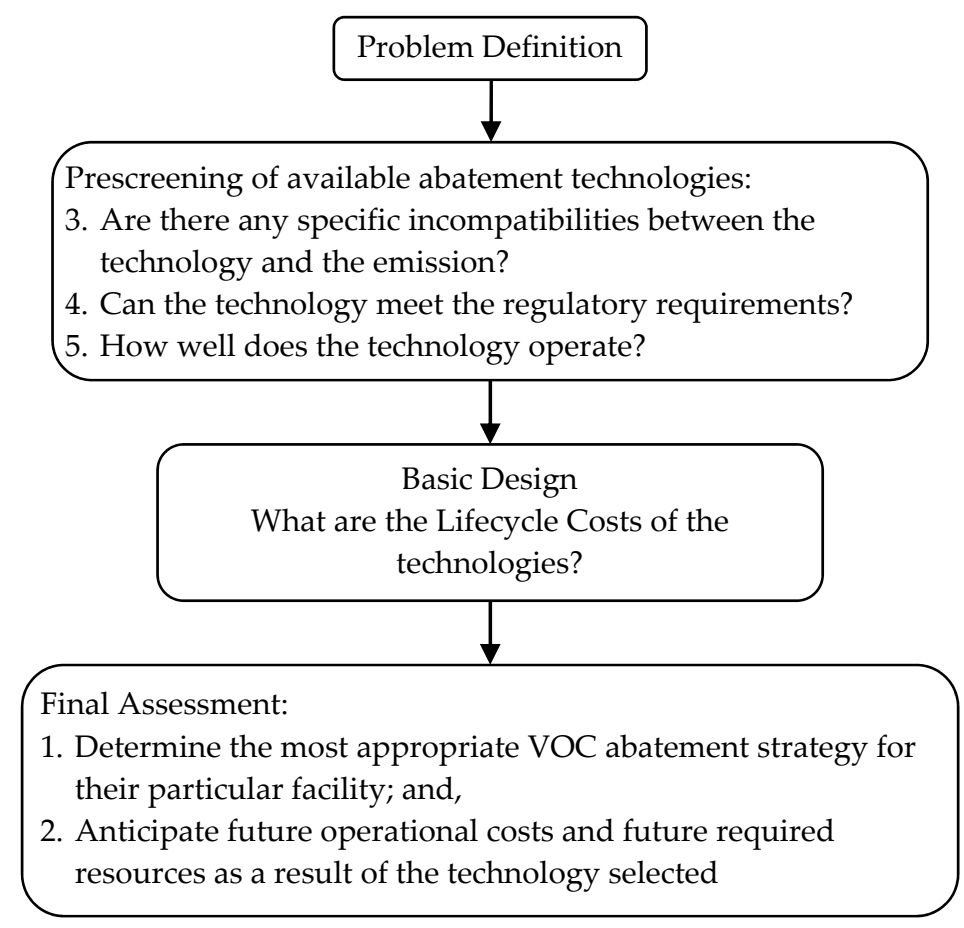

Figure 5. VOC abatement technology selection flow sheet.

\subsection{Problem definition}

The problem definition is the step in which all preliminary data required to assess the issue is found. This means defining four key elements: the emission source, the emission itself, legal requirements that must be met, and any budgetary constraints. In almost all cases, this data is readily available at the facility, and can be compiled quickly.

\subsection{Prescreening}

As outlined in Figure 6, the prescreening step answers three questions: 
1. Are there any specific incompatibilities between the technology and the emission?

2. Will the technology meet the current regulatory requirements?

3. How well does the technology operate (technology robustness, and technology flexibility)?

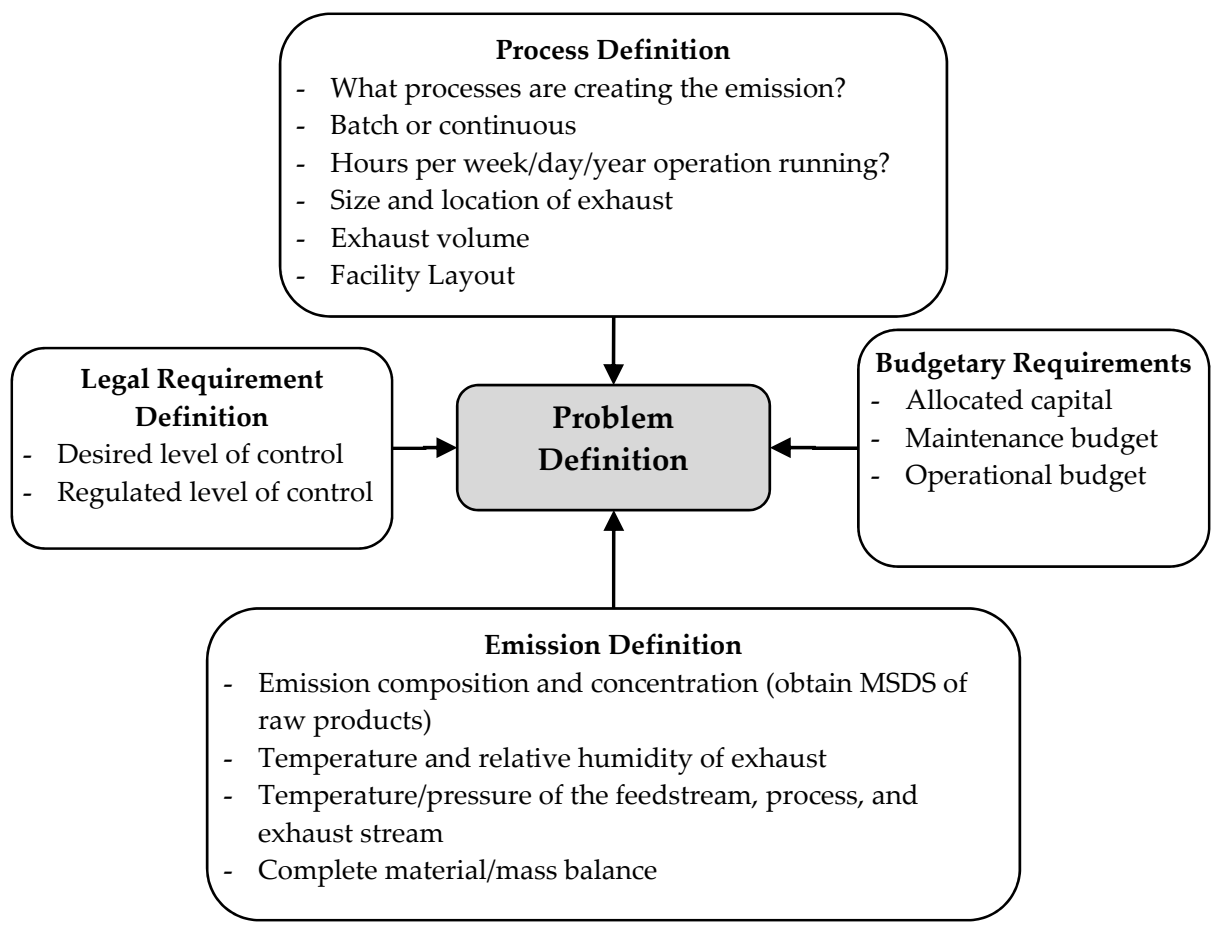

Figure 6. Information recommended when defining industrial emission problems.

The idea behind the prescreening step is to compare the information compiled from the problem definition with all the limitations found in literature on the abatement technologies considered. This will allow facility management to discard technologies from consideration that don't meet their prescribed criteria, and thus shorten the number of technologies required to undergo the basic design step.

For instance, if it was found that the emission contained significant amounts of acidic gases (such as chlorine or sulfur compounds), certain regenerative catalytic thermal oxidation techniques may not be feasible (unless a scrubber step was implemented prior to the combustion chamber) as the catalysts would be poisoned (Baukal, 2004).

Can technology meet current regulatory requirements?

The concern is if the system can lower the emission rate below the regulatory threshold, and if future regulatory requirements are identified, can the system maintain the facility's 
emission output below this future threshold. In Ontario Canada, it is considered good industry practice to design systems to reduce emissions below $50 \%$ of the current threshold ensuring the technology will be able to be used for the entire lifespan of the system. In this work, to obtain a quantitative measurement of how well each technology handles regulatory requirements, the matrix outlined in Table 2 will be used.

\begin{tabular}{cl}
\hline Score & \multicolumn{1}{c}{ Description } \\
\hline 3 & Meets current and foreseeable future regulations and requirements \\
2 & Meets current regulations and requirements \\
1 & Does not meet current regulations and requirements \\
\hline
\end{tabular}

Table 2. Matrix outlining regulatory scoring requirements.

How well does the technology operate?

The ability of an abatement technology to smoothly incorporate process or facility changes in its operation is a function of how the basic technology works, and not the size of the facility or the emission composition used for the design phase. This is the Operational Flexibility of the technology, and can be assessed by examining the following factors:

1. Start-up times

2. Continuous vs Intermittent Operation

3. Load Tolerance

a. Ability to handle fluctuations in emission concentration or emission types; and,

b. Ability to handle fluctuations in total flow

The scoring matrices listed in Tables 3 through 5 outline how each type of abatement technology will be quantifiably assessed for operational flexibility.

\begin{tabular}{cl}
\hline Score & \multicolumn{1}{c}{ Description } \\
\hline 3 & Start-up quicker then $1 / 2$ production shift \\
2 & Start-up quicker then 1 production shift \\
1 & Start-up takes longer than 1 production shift \\
\hline
\end{tabular}

Table 3. Scoring system used to assess start-up timing for each type of abatement technology.

\begin{tabular}{cl}
\hline Score & \multicolumn{1}{c}{ Description } \\
\hline 3 & Intermittent Operation or cycling ok \\
2 & Moderate Toleration to Intermittent operation \\
1 & Does not tolerate intermittent operation \\
\hline
\end{tabular}

Table 4. Scoring system used to assess operational flexibility in terms of continuous vs intermittent operation for the abatement technologies. 


\begin{tabular}{cl}
\hline Score & \multicolumn{1}{c}{ Flow or Concentration } \\
\hline 3 & Tolerates fluctuations \\
2 & Tolerates minor fluctuations \\
1 & Does not tolerate flucuations \\
\hline
\end{tabular}

Table 5. Scoring system used to assess operational flexibility in terms of load tolerance for the abatement technologies.

\subsection{Basic design}

Once the prescreening step is complete, the list of feasible technologies for further investigation will be relatively small. A basic design for each of the technologies under consideration can now be completed. The purpose of the basic design is to determine the size and main operational requirements (utilities) of the system. The size will be used to obtain a good estimate of the capital costs, and the operational requirements will be used to determine the annual operating costs. Together, with the implementation of proper engineering economics, a lifecycle cost for the abatement system can be determined.

When determining lifecycle costs there are many things that need to be considered to ensure that a full assessment can be made. For this particular assessment the lifecycle cost calculation will include the following:

1. Capital costs

2. Resource costs (natural gas, electricity, water)

3. Labour and maintenance costs

4. Anticipated major maintenance costs

5. Land use costs; and,

6. Anticipated lifespan

It is important to note that land use costs are very complex in nature and are highly dependent upon the geographic location, whether new land was required to be purchased, or existing land could be used, and what type of construction would be required. For this reason, the land use costs used in the following case study are based on data found for the City of Toronto for industrial land $\left(\$ 110 / \mathrm{m}^{2}\right)$. Other locations may have significantly different land costs.

\subsection{Final assessment}

Up to this point, a prescreening assessment has been completed to eliminate technologies not able to meet the following minimum constraints. Furthermore, qualitative operational criteria and the ability of an abatement technology to meet legislative requirements have been quantified into numerical values for objective comparisons, and a basic lifecycle cost estimate has been created. At this stage the information is compiled into a meaningful way so facility management will be able to make a clear and informed decision on the abatement strategy they wish to pursue. In this analysis, there is only one constraint and two criteria to 
base the decisions on. These scores can all be multiplied together to get an overall score assessing non-economic performance, and the lifecycle costs can be used to consider economic considerations. To illustrate the methodology, a case study using this Technology Assessment Tool for a typical facility is presented in the following section.

\section{Technology assessment: Case study}

\subsection{Problem definition}

Overall Prescreening Summary. The information in Table 6 illustrates the types of contaminants in the emission stream, the approximate concentration, the total flow rate, and the type of operation. Temperature for the coating preparation and spray application is typically between $20^{\circ} \mathrm{C}$ and $25^{\circ} \mathrm{C}$. Humidity can vary depending on the operation, but it is assumed the relative humidity $(\mathrm{RH})$ of the system is approximately $75 \%$. It is also assumed that the target emission load reduction is $50 \%$ of current levels.

Industrial coating operations using solvent based coatings are typically composed of high volume low concentration exhaust streams of components with relatively low boiling points. Condensation systems are limited to operations above 5,000 ppm in concentration and to solvents with boiling points above 5,000 ppm (Khan \& Ghoshal, 2000; Kohl \& Nielsen, 1997). The concentration of the emissions listed in Table 6 are all well below this $5,000 \mathrm{ppm}$ threshold. Under these conditions condensation systems do not operate efficiently because the energy required to condense the component emissions would be substantial.

\begin{tabular}{cl}
\hline Definition & \multicolumn{1}{c}{ Facility Information } \\
\hline Emission & 15\% Xylene \\
Definition & 35\% Methyl Ethyl Ketone \\
& $40 \%$ Toluene \\
& 10\% N-Butyl Acetate \\
\hline Process & 1.) Process: Automotive trim parts painting \\
Definition & 2.) Continuous process \\
& 3.) Annual Hours of Operation: 240 days @ 16 hrs/day annually \\
& Flow: 60,000 cfm \\
& Emission: 100 tonnes VOCs \\
\hline Budget & Lifecycle costs will be compared using net present value costs for each \\
Definition & technology \\
\hline *Legal & Federal Reporting Program National Pollutant Release Inventory \\
Requirement. & (NPRI), Ontario Regulations 419 and 127 \\
\hline
\end{tabular}

*Legal requirements are based upon the province/state/country the facility resides in. In this case, we are considering the geographical location to be Southern Ontario, Canada.

Table 6. Problem definition for the three sample facilities considered. 
Furthermore, industrial coating operations emit highly variable and complex emission streams in which a suitable absorbing liquid is difficult to find. The result is that in this case, absorption systems will not operate efficiently either, and therefore are not considered further.

In summary, under the conditions listed, only the following technologies will be reviewed for the facility listed in Table 6: RTO and RCO (Regenerative and Recuperative types), Biological Oxidation, and Carbon Adsorption.

\subsection{Basic design: Thermal oxidation assessment}

Regulatory Requirements. Thermal oxidation systems are rated with destruction efficiencies that range between 95\% - 99\%. When properly designed and operated, a thermal oxidation system will always be able to remove the contaminants below the prescribed emission limit. Even if regulatory threshold values were to decrease substantially, these rated destruction efficiencies ensure that the system would be able to maintain a consistent reduction. The only foreseeable problem is if regulatory thresholds were established for carbon dioxide, carbon monoxide, and/or nitrogen oxides. In this case, because the thermal reaction involves the transformation of VOCs to these specific contaminants, the facility would have to ensure that they are monitoring these emissions as well. Based upon the matrix outlined in Table 2, the numerical value associated with this criterion is 3 .

Lifecycle Costs. In order to determine the lifecycle costs for thermal oxidation abatement systems, the capital and operational costs must be established. For the sample facility, the operational and capital costs were calculated using the EPA methodologies (EPA, 2002). Finally, to update 1994 capital costs to more current figures (2009 dollar values), the appropriate Marshall \& Swift equipment cost indices were used (Cooper and Alley, 2011).

The capital and operational costs to purchase and operate the various thermal abatement systems outlined here are described in Table 7.

As expected, the recuperative type RTO, which is the least technologically advanced has a substantially lower capital investment, but requires significantly more money to operate due to its poorer energy recovery capabilities. Similarly, the RCO (catalytic system), has the highest capital cost, but a significantly lower operating cost, since it operates at lower temperatures.

Therefore, as a business case, the choice between which thermal system to use now becomes a choice between the Regenerative type RTO or the Recuperative RTO. A lifecycle analysis was completed to differentiate between each system and obtain a true cost comparison. The lifecycle analysis was determined using a discount rate of $3 \%$ which is outlined in the NIST Handbook 135 Life-cycle costing Manual for the Federal Energy Management Program (Fuller \& Petersen, 1996), and the results are shown in the bottom row of Table 7, as a net present value (or cost in this case), over a ten year period.

Therefore, although the Recuperative technology is a substantially lower capital investment, and the catalytic oxidation system is overall the most economically feasible system for these particular emission scenarios. 


\begin{tabular}{|c|c|c|c|c|}
\hline $\begin{array}{l}\text { Purchased and installed } \\
\text { equipment costs: }\end{array}$ & Factor & Recuperative & Regenerative & Catalytic \\
\hline Incinerator (1994) & & 197,400 & 810,000 & 662,474 \\
\hline Incinerator (2009) & 1.496 & 295,310 & $1,211,760$ & 991,061 \\
\hline $\begin{array}{l}\text { Instrumentation, } \\
\text { freight }\end{array}$ & 0.28 & 82,687 & 339,293 & 277,497 \\
\hline
\end{tabular}

Direct installation costs included in purchase

\begin{tabular}{|c|c|c|c|c|c|}
\hline \multicolumn{3}{|c|}{$\begin{array}{l}\text { Subtotal Direct Installation } \\
\text { Costs }\end{array}$} & 377,977 & $1,551,053$ & $1,268,558$ \\
\hline \multicolumn{2}{|c|}{ Indirect Costs } & 0.31 & 91,546 & 375,646 & 307,229 \\
\hline \multicolumn{3}{|c|}{ Total Installation Costs } & 469,544 & $1,926,698$ & $1,575,787$ \\
\hline \multicolumn{6}{|c|}{ Direct Annual Costs } \\
\hline \multirow[t]{2}{*}{ Utilities } & Fuel & & $1,755,700$ & 658,500 & 348,000 \\
\hline & Electricity & & 267,200 & 264,700 & 238,500 \\
\hline \multirow[t]{2}{*}{ Labour } & Supervisor $15 \%$ o & & 1,248 & 1,248 & 1,248 \\
\hline & Labour & & 8,320 & 8,320 & 8,320 \\
\hline \multicolumn{3}{|c|}{ Maintenance } & 23,477 & 96,335 & 78,789 \\
\hline \multicolumn{3}{|c|}{ Subtotal Direct Costs } & $2,052,945$ & $1,029,103$ & 674,857 \\
\hline \multicolumn{2}{|c|}{ Overhead on labour } & 0.6 & 5,741 & 5,741 & 5,741 \\
\hline \multicolumn{2}{|c|}{ Taxes, insurance, depreciation } & 0.12 & 56,345 & 216,905 & 189,094 \\
\hline \multicolumn{3}{|c|}{ Subtotal Indirect Costs } & 62,086 & 222,646 & 194,835 \\
\hline \multicolumn{3}{|c|}{ Total Annual Costs } & $2,118,031$ & $1,251,749$ & 869,693 \\
\hline \multicolumn{3}{|c|}{ Lifecycle Cost } & $18,523,103$ & $12,548,252$ & $8,948,543$ \\
\hline
\end{tabular}

Notes: a.) The operational costs calculated here do not include the cost to keep the systems hot during non-production working times (8 hours per day).

Table 7. Thermal treatment systems cost analysis.

Operational Flexibility. The operational flexibility of thermal oxidation systems is moderate. Start-up times are dependent upon the time it takes to get the combustion chamber to reach the combustion temperature. From a dormant state, thermal systems typically take 4 to 6 hours to reach combustion temperatures.

In terms of load tolerance, thermal oxidative systems are generally good because they can destroy virtually all VOC compounds provided the combustion temperature is above the auto-ignition temperature of all species in the mixture. The problem comes when varying the emission concentration or total flow rate. In practice, some VOC mixtures have enough 
energy to sustain combustion, provided heat recovery of the system is at a sufficient level. Kohl and Nielsen provide a figure outlining this relationship, and from it, one can interpolate that at a heat recovery percentage of $95 \%$, the VOC concentration would need to be approximately $3 \%$ of the LEL to sustain combustion (Kohl \& Nielsen, 1997). This means, in theory no supplementary natural gas is required, thereby lowering operational costs. For example, if the VOC mixture was initially at a concentration of $3 \%$ of the LEL, and was lowered due to production changes, large amounts of supplementary natural gas will be required, and operational costs could become prohibitive (this is the case for the three sample facilities described here).

On the other hand, if emission concentrations are raised significantly due to production variations (above 25\% LEL), dilution air may be required to be added to the system. This would increase the overall flow rate, changing design requirements, which will result in an in-efficient destruction of the VOC compounds.

Therefore, in terms of concentration changes, the system has a fairly wide range of tolerance. Conversely, as previously mentioned, thermal oxidation systems are not suited to highly variable flow rates. The design of the system incorporates the flow rate to establish appropriate residence times and mixing of the exhaust stream. As a result, changing the flow rate may result in the incomplete combustion of the emission. Simply put, thermal oxidation systems are intolerant to flow rate changes and tolerant to changes in concentration.

Lastly, thermal oxidation systems are limited to processes that continually operate. If continuous operation is not possible, systems can be run intermittently if the system is kept hot during off hours. This is accomplished by continuously combusting natural gas in the oxidation chamber. This prevents the bed cycling between hot and cold temperatures, which will prevent cracking of the heat exchanger beds. Overall, operational flexibility scores for thermal technologies are outlined in Table 8:

\begin{tabular}{lcccc}
\hline $\begin{array}{c}\text { Abatement } \\
\text { System }\end{array}$ & $\begin{array}{c}\text { Start-up } \\
\text { times }\end{array}$ & $\begin{array}{c}\text { Continuous vs } \\
\text { intermittent } \\
\text { operation }\end{array}$ & $\begin{array}{c}\text { Flexibility: Flow } \\
\text { tolerance }\end{array}$ & $\begin{array}{c}\text { Flexibility: Conc. } \\
\text { tolerance }\end{array}$ \\
\hline RTO (Recup.) & 2 & 2 & 1 & 3 \\
RTO (Regen.) & 2 & 2 & 1 & 3 \\
RCO & 2 & 2 & 1 & 3 \\
\hline
\end{tabular}

Table 8. Overall operational flexibility scores for thermal oxidation abatement technologies.

\subsection{Basic design: Biological oxidation assessment}

Regulatory Requirements. For the three sample facilities in this analysis the removal efficiency (termed destruction efficiency for RTO's) for biological oxidation processes is substantially lower than that of thermal oxidation and adsorption abatement techniques. Despite this, 
biological oxidation systems can meet regulatory thresholds. Meeting regulatory thresholds only refers to reducing the given facility's emission output for a specific contaminant below the prescribed limit. If the facility in question was emitting pollutants barely above the facility limits, then the level of reduction required would be quite small. For this reason, a removal efficiency of $50 \%$ or lower may be satisfactory. The only issue this may present is if regulatory bodies substantially lower emission limits in the future.

Lifecycle Costs. Operational costs are normally quite low for these systems because the temperature and pressure will remain close to ambient conditions. The largest energy input is the power required to circulate the emission through the bed. Therefore, provided the bed is maintained appropriately, the operational cost should not be high. The problem comes when assessing the overall space requirement for these systems. Mass transfer limitations require that contact areas (bed surface areas) are large. After associating the required space with an appropriate monetary value (lease or purchase cost), the lifecycle cost of this system can become substantial. Tables 9 and 10 summarize the capital and operational costs. The

\section{Site Costs}

Height $x$ Length $x$ Width $(m)$

Area $\left(\mathrm{m}^{2}\right)$

Gravel Requirements height (m):

Gravel Requirements $\left(\mathrm{m}^{3}\right)$

Total Volume Required $\left(\mathrm{m}^{3}\right)$

Total Site Cost(equipment, labour, overhead)

\section{Media Costs}

Assume $\$ 37 / \mathrm{m}^{3}$ for compost

Assume $\$ 33 / \mathrm{m}^{3}$ for gravel

Assume $\$ 2.5 / \mathrm{m}^{3}$ installation costs

\section{Equipment Costs}

Blower and tower humidifier:

Piping, design, electrical, installation ( $18 \%$ of capital costs):

Liner Cost

Total Equipment Costs

Table 9. Open Bed Biofilter Capital Cost Summary 


\section{Electricity}

Superficial Velocity (m/s)

Pressure drop $(\mathrm{Pa} / \mathrm{m})$

Blower horsepower (HP)

Blower (kWh)

Annual Pump Electrical (assume $2 \mathrm{HP}$ ) (kWh)

10800

Total Cost ( $\mathrm{kWh} \times \$ 0.08$ per $\mathrm{kWh})$

$\$ 100,481$

Water for humidification $\left(\mathrm{m}^{3}\right)$

Cost of water $\$ 0.7 / \mathrm{m}^{3}$

Labour (assume 2 hours per day @ \$20/hr)

Overhead (60\% of Labour)

Insurance, property taxes

Depreciation (equipment only, not land)

Media Replacement (3 year cycle annualized)

Total Miscellaneous Cost:

Table 10. Annual Biofilter (Open Bed) Operational Costs

costing process used to calculate the biofilter capital and operational costs were taken from Devinny et al. (1999). Furthermore, the lifecycle analysis was determined using a discount rate of 3\% (Fuller \& Petersen, 1996) as previously, resulting in a net present value (cost) of $\$ 2,644,000$ based on the 10 year period.

Operational Flexibility. The key to understanding biological oxidative technologies is in performing a thorough literature search to determine experimental parameters such as the removal efficiencies for specific contaminant and media configurations. These experimental parameters are then used to create a pilot design for testing. Once the pilot system is tested a better understanding of the overall performance can be established. In this analysis, the cost of performing trials is not explicitly outlined, however, it is considered as part of the engineering design fees. Operational considerations, such as system robustness, start-up times, and load tolerance can be tested and evaluated before the implementation of a full scale system is undertaken.

Biological systems are generally not as robust as other systems. Times required to achieve steady state performance may vary between several days to several months (Devinny et al., 1999). This is specifically due to the kinetics associated with biological processes and startup conditions. Biofilters are not very tolerant of load variations either. In biofilters, the main source of energy for the microbial population's anabolic and metabolic processes comes 
from the VOC that is fed to the biofilter (Delhoménie \& Heitz, 2005). Therefore if there is a large decrease in VOC loading, the microbial population may begin to starve. If the microbial population does die, the entire bed would require replacement or re-inoculation. This in effect, would cause a significant disruption in production and could be a very expensive endeavor.

If the VOC load is increased one of two problems may occur:

1. The microbial population cannot destroy enough of the VOC emission to maintain the regulatory limit because they have reached their maximum elimination capacity; and/or,

2. The microbial population's growth rate rapidly increases, substantially increasing microbial wastes in the media, potentially creating a toxic environment for the microbial population, or increased pressure drop.

Both situations would result in significant performance issues that would require considerable resources to remedy.

Biofilters can be somewhat resilient to intermittent operation, provided some contaminant has been adsorbed into the media. This adsorbed contaminant can be utilized by the microbial population during downtime, or off shift periods. The actual level of resilience cannot be quantified unless pilot studies are completed. Table 11 outlines the Biofilter's operational flexibility scores.

\begin{tabular}{ccccc}
\hline $\begin{array}{c}\text { Abatement } \\
\text { System }\end{array}$ & $\begin{array}{c}\text { Start-up } \\
\text { times }\end{array}$ & $\begin{array}{c}\text { Continuous vs } \\
\text { intermittent } \\
\text { operation }\end{array}$ & $\begin{array}{c}\text { Flexibility: Flow } \\
\text { tolerance }\end{array}$ & $\begin{array}{c}\text { Flexibility: Conc. } \\
\text { tolerance }\end{array}$ \\
\hline Biofilter & 1 & 3 & 1 & 1 \\
\hline
\end{tabular}

Table 11. Operational flexibility scores for the biofilter.

\subsection{Basic design: Adsorption system assessment}

Regulatory Requirements. Similar to the thermal oxidation systems, removal efficiencies can be quite high (over 95\%) and provided the system is sized appropriately, it should always be able to reduce the contaminant loading well below the regulatory threshold.

Lifecycle Costs. The principal operation of this system is solvent recovery. For the purposes of the sample facilities described, solvent recovery will not be considered possible because the quality of the product will likely be poor, however, it should still be examined, as the recovered solvent may have a second market providing an extra revenue stream for the facility.

As with the thermal abatement systems, the lifecycle costs can only be established after capital and operating costs are determined. In this case, capital costs were established using EPA methodologies (EPA, 2002), and the operational costs were established using 
recommended procedures (Cooper \& Alley, 2002). Lifecycle costs were then established using a discount rate of 3\% (Fuller \& Petersen, 1996) as described previously. Table 12 describes the calculated capital and operational costs, concluding with the lifecycle cost as indicated for the previous technologies.

\begin{tabular}{|c|c|c|c|c|}
\hline \multicolumn{3}{|c|}{ Purchased and installed equipment costs: } & Factor & Cost (\$) \\
\hline \multicolumn{3}{|c|}{ Vessel Cost } & & 55,100 \\
\hline \multicolumn{3}{|c|}{ Carbon Cost } & & 21,700 \\
\hline \multicolumn{3}{|c|}{ Equipment Cost (1994 Costs) } & & 473,500 \\
\hline \multicolumn{3}{|c|}{ Equipment Cost (2009 Costs) } & 1.496 & 708,356 \\
\hline \multicolumn{3}{|c|}{ Taxes, freight } & 0.18 & 127,504 \\
\hline \multicolumn{3}{|c|}{ Foundations, erection, electrical, piping, painting } & 0.44 & 311,677 \\
\hline \multicolumn{3}{|c|}{ Subtotal Direct Installation Costs } & & $\$ 1,147,537$ \\
\hline \multicolumn{3}{|c|}{ Indirect Installation Costs } & 0.31 & 219,590 \\
\hline \multicolumn{3}{|c|}{ Total Installation Costs } & & $\$ 1,367,127$ \\
\hline \multicolumn{5}{|c|}{ Direct Annual Costs } \\
\hline \multirow[t]{3}{*}{ Utilities } & \multicolumn{2}{|c|}{ Steam (Gas Cost) } & & 41,200 \\
\hline & \multicolumn{2}{|l|}{ Water Cost } & & 66,200 \\
\hline & \multicolumn{2}{|c|}{ Electricity (system fan) } & & 12,900 \\
\hline \multirow[t]{2}{*}{ Labour } & Labour & $8 \mathrm{hr} /$ week & $\$ 20 / \mathrm{hr}$ & 7,680 \\
\hline & Supervision & $15 \%$ of labour & & 1,152 \\
\hline \multicolumn{4}{|c|}{ Maintenance } & 68,356 \\
\hline \multicolumn{3}{|c|}{ Solvent Disposal } & & 166,300 \\
\hline \multicolumn{4}{|c|}{ Subtotal Direct Costs } & $\$ 364,524$ \\
\hline \multicolumn{3}{|c|}{ Overhead (labour) } & 0.6 & 5,741 \\
\hline \multicolumn{3}{|c|}{ Taxes, insurance, depreciation } & 0.12 & 164,055 \\
\hline \multicolumn{3}{|c|}{ Subtotal Indirect Costs } & & $\$ 169,796$ \\
\hline \multicolumn{3}{|c|}{ Total Annual Costs } & & $\$ 534,320$ \\
\hline \multicolumn{3}{|c|}{ Lifecycle cost } & & $\$ 5,885,169$ \\
\hline
\end{tabular}

Table 12. Adsorption system cost analysis

Operational Flexibility. The adsorption process takes place at near ambient pressure and temperature. Therefore as long as enough carbon beds are available for operation, start-up times will be fast. 
In terms of design, the carbon requirement dictates the overall load that can be treated, and once the system is sized it is very difficult to make alterations for different loading levels or different flow rates. Therefore if the load is increased substantially, the system will not be able to handle the increase in load unless the overall configuration of the system is changed. Cycling and regeneration times would have to be re-calculated, and in extreme cases these changes may not be feasible. On the other hand, if the load was reduced substantially, the system would simply operate inefficiently incurring higher than expected operational costs.

Moreover, changes in load composition pose other unique problems. The original design of these systems relies on the adsorption characteristics for the most difficult species to adsorb. If a new compound was added into the emission mixture with poorer adsorption characteristics, a breakthrough situation may occur during operation. The system would have to be redesigned according to the new compound's adsorption characteristics.

Conversely, this system can operate both continuously and intermittently. This offers the advantage of not using extra energy to operate the system when production is down, or to start-up the systems when production times fluctuate substantially.

Overall, adsorption systems are moderately tolerant to flow rate variations, fairly intolerant to changes in emission composition, and very tolerant to intermittent vs continuous operational strategies. Table 13 outlines the operational flexibility scores for adsorption based VOC abatement technologies.

\begin{tabular}{c|cccc}
\hline $\begin{array}{c}\text { Abatement } \\
\text { System }\end{array}$ & $\begin{array}{c}\text { Start-up } \\
\text { times }\end{array}$ & $\begin{array}{c}\text { Continuous vs } \\
\text { intermittent } \\
\text { operation }\end{array}$ & $\begin{array}{c}\text { Flexibility: Flow } \\
\text { tolerance }\end{array}$ & $\begin{array}{c}\text { Flexibility: Conc. } \\
\text { tolerance }\end{array}$ \\
\hline Adsorption & 3 & 3 & 2 & 1 \\
\hline
\end{tabular}

Table 13. Operational flexibility scores for adsorption abatement systems.

\subsection{Final analysis}

The Technology Assessment presented here is a resource to aid facility managers in determining which VOC abatement strategy would be most applicable for their particular facility. To do this, criteria scores and lifecycle costs are compared. For the final comparison it is up to facility management to determine which criteria holds the most weight. A typical order of importance would be: Regulatory Compliance, Lifecycle Costs, and finally, Operational Flexibility.

\subsubsection{Regulatory compliance}

Thermal oxidation systems are rated with destruction efficiencies that range between 95\% 99\%. Properly designed, a thermal oxidation system will always be able to remove the contaminants below the prescribed emission limit. Even if regulatory threshold values were 
to decrease substantially, these rated destruction efficiencies ensure that the system would maintain a consistent reduction. The only foreseeable issue is if regulatory thresholds were established for carbon dioxide, carbon monoxide, and/or nitrogen oxides.

For biological oxidation processes the elimination capacity of $\mathrm{VOC}^{\prime} \mathrm{s}$ is substantially lower than that of thermal oxidation and adsorption abatement techniques. Despite this, biological oxidation systems can meet regulatory thresholds. Meeting regulatory thresholds means: reducing the given facility's emission output for a specific contaminant below the prescribed limit. In the example case, literature reports that elimination capacities range between $60 \%$ and $80 \%$. Therefore if the emissions exhausted from the facility were up to $60 \%$ above the legislated limit, the Biofilter would be able to meet the legislated requirements. In this particular case, it is assumed that the emissions exhausted are within this range, and therefore the Biofilter can meet the current legislated requirements.

Similar to RTO's, removal efficiencies for Adsorption systems can be quite high. A typical adsorption system can maintain removal efficiencies up to $95 \%$ provided there are no VOCs in the mixture with a particularly poor adsorption isotherm for the adsorbent being used. This means that even if emission limits were to become more stringent, Adsorption systems should be able to meet. In summary, in terms of Regulatory Compliance, these systems are compared numerically in Table 14, based on the rating system outlined in Table 2.

\begin{tabular}{cc}
\hline Abatement System & Regulatory Compliance \\
\hline Regenerative Thermal Oxidation & 3 \\
Biofilter & 2 \\
Adsorption & 3 \\
\hline
\end{tabular}

Table 14. Regulatory Compliance Score Summary for Abatement Technology Analysis of three Sample Facilities.

\subsubsection{Lifecycle costs}

The Lifecycle cost based on a 10 year life expectancy for each abatement system and each sample facility is summarized in Table 15.

\begin{tabular}{cc}
\hline Abatement System & Net Present Value (cost) \\
\hline Regenerative Thermal Oxidation & $\$ 12,548,252$ \\
Biofilter & $\$ 2,644,000$ \\
Adsorption & $\$ 5,885,169$ \\
\hline
\end{tabular}

Table 15. Net Present Value (Costs) for Abatement Technology Analysis of three Sample Facilities (at $3 \%)$ 
The Biofilter system is the most economical to operate, over the life span of the technology, while the thermal oxidation is the least. However, it must be emphasized that this may not be a general trend. These costs could vary significantly depending on the starting parameters such as exhaust flow rates and emission concentrations, the geographic area considered, or even purity and value of recovered solvent.

\subsubsection{Operational flexibility}

The numerical rating for each Operational Flexibility characteristic is listed in Table 16, where the technology with the highest total is the most favourable according to this rating scheme.

\begin{tabular}{lccccc}
\hline $\begin{array}{c}\text { Abatement } \\
\text { System }\end{array}$ & $\begin{array}{c}\text { Start-up } \\
\text { times }\end{array}$ & $\begin{array}{c}\text { Continuous vs } \\
\text { intermittent } \\
\text { operation }\end{array}$ & $\begin{array}{c}\text { Flexibility: } \\
\text { Flow } \\
\text { tolerance }\end{array}$ & $\begin{array}{c}\text { Flexibility: } \\
\text { Conc. } \\
\text { Tolerance }\end{array}$ & Total \\
\hline RTO (Regen.) & 2 & 2 & 1 & 3 & 12 \\
Biofilter & 1 & 3 & 1 & 1 & 3 \\
Adsorption & 3 & 3 & 2 & 1 & 18 \\
\hline
\end{tabular}

Table 16. Operational Flexibility Scores summarized for the Abatement Technology Analysis of three sample facilities.

Overall, the Adsorption systems appear to have the best operational flexibility rating. This is because they are easy and quick to start up, and they have the ability to treat both continuous and intermittent processes. Conversely, minor design and cycling considerations may be required if concentrations in the emission are changed, whereas major design changes may need to be considered should the emission composition change. This is because although adsorption systems can be designed to operate efficiently for a given set of parameters, it is typically unknown how well the system would perform with mixed species until laboratory and pilot studies are performed, or a well known isotherm has been established for that particular contaminant with the adsorbent being used.

RTO systems are relatively easy to operate, and are fairly tolerant to changes in emission concentration and composition. These systems do not handle fluctuations in flow rate well, and although they work efficiently in continuous operation, during intermittent operations system performance may be compromised as a result of how major temperature fluctuations affects the ceramic heat exchanger. This problem can be mitigated by keeping the system hot during off hours with a steady flow of natural gas. This of course will increase facility operational costs, and thus, the flexibility in this category was downgraded.

Operationally, the Biofilter system is potentially the least flexible. Start-up times could be quite long, and changes in emission flows or concentrations would have unpredictable 
effects on the microbial population. Essentially this means in comparison to the other technologies, the Biofilter system may be difficult to maintain in sustained operation.

\section{Conclusion}

The Technology Assessment created for the sample facility profile listed in Table 6 indicates the following:

1. The Adsorption system has a moderate lifecycle cost, and is the most operationally flexible. Major design changes would be required should changes in emission compositions or concentrations occur.

2. The RTO system has the highest lifecycle cost, and is moderately operationally flexible. Major design changes would be required should process flow rates be changed.

3. The Biofilter has the lowest lifecycle cost, but has the least operational flexibility, and may require a full design change if regulatory limits are significantly decreased.

For these sample facilities, it is likely facility management will choose between the Adsorption system and the RTO. The decision between the two systems will depend on the relative importance facility management places on lifecycle costs vs operational flexibility. Which is more important will depend on future business forecasts. For instance, if customer coating requirements are expected to change, such as coating compositions or concentrations, then the RTO may be a more suitable abatement system because it can essentially destroy any VOC with the same destruction efficiency and would be able to function as is despite these changes in the emission stream.

It is important to note that this case study Technology Assessment is only valid for these sample facilities, and this specific geographic area. At any given facility, emissions exhausted may have differing compositions, concentrations, and flow rates. Legislative requirements prescribed in various regions differ, and each geographic area will have different land values associated with them. Three examples of this are provided as follows:

1. If the VOC concentration was high enough to sustain combustion for the thermal oxidation systems, the operational costs would have been substantially lowered.

2. If the geographic area of the facility was associated with lower land values, the Biofilter would have substantially lower lifecycle costs.

3. If the purity of the solvent recovered by the Adsorption system was suitable for resale, the cost associated with disposal of the solvent would be negligible, and a new revenue stream could be developed that reduces the lifecycle costs.

These different scenarios outline the need for the Abatement Technology Assessment technique developed here. Using this systematic approach facility management will able to predict the functionality and cost associated with implementing abatement technologies on existing facilities. Overall this ensures the decision will be based upon the most pertinent factors associated with the facility. 


\section{Author details}

Dhananjai S. Borwankar, William A. Anderson, and Michael Fowler Department of Chemical Engineering, University of Waterloo, Canada

\section{References}

Baukal, C. E. (2004). Industrial combustion pollution and control; Environmental science and pollution control series: 27; Marcel Dekker, New York.

Cape, J. N. (2008). Interactions of forests with secondary air pollutants. Environmental Pollution, 155, pp. 391-397.

Cooper, C. D., Alley, F.C., (2002) Air pollution control: a design approach; Waveland Press: Prospect Heights, Ill.

Cooper, C. D., Alley, F.C., (2011). Air pollution control: a design approach, $4^{\text {th }}$ edition; Waveland Press: Prospect Heights, Ill.

Delhoménie, M.; Heitz, M. (2005). Biofiltration of Air. Critical Reviews in Biotechnology, 25, pp. 53-72.

Devinny, J. S.; Deshusses, M. A.; Webster, T. S. (1999). Biofiltration for air pollution control; Lewis Publishers: Boca Raton, Fl.

Doble, M.; Kumar, A. (2005). Biotreatment of Industrial Effluents. Elsevier ButterworthHeinemann, Oxford, U.K.

EPA. (2002). EPA Air Pollution Control Cost Manual (6 $6^{\text {th }}$ edition). U.S. Evironmental Protection Agency, Research Triangle Park, North Carolina.

Farley, J. M. (1992). Inhaled toxicants and airway hyperresponsiveness. Annu. Rev. Pharmacol. Toxicol., 32, pp. 67-88.

Fuller, S. K.; Petersen, S. R. (1996). NIST Handbook 135: Life-Cycle Costing Manual for the Federal Energy Management Program; National Institute of Standards and Technology, Washington, DC.

Gibson, D., (1999). A burning issue : Putting the heat on air pollutants. Chem. Eng., 106, pp. 45-53.

Khan, F. I.; Ghoshal, A. K. (2000). Removal of Volatile Organic Compounds from polluted air. J. Loss Prevention in the Process Industries, 13, pp. 527-545.

Knaebel, K., S. (2007). A "How to" Guide for Adsorption Design; Adsorbent Research Inc. Dublin, Ohio.

Kohl, A. L.; Nielsen, R. (1997). Gas Purification (5 ${ }^{\text {th }}$ edition). Gulf Professional Publishing, Houston, TX.

Lewandowski, D. A. (2000). Design of thermal oxidation systems for volatile organic compounds; Lewis Publishers: Boca Raton, Fla.; London.

Malhautier, L.; Khammar, N.; Bayle, S.; Fanlo, (2005). Biofiltration of volatile organic compounds. J. Appl. Microbiol. Biotechnol., 68, pp. 16-22.

Moretti, E. C. (2002). Reduce VOC and HAP emissions. Chem. Eng. Prog., 98, pp. 30-40. 
Shelley, S.; Pennington, R., L.; Lisewski, M. (1999)., Get More From Your Regenerative Thermal Oxidizer. Chemical Engineering, 106, pp. 137.

U.S. Army Corps of Engineers. (2005). Adsorption Design Guide; DG 1110-1-2; University Press of the Pacific. 